\title{
Distinct glutaminyl cyclase expression in Edinger-Westphal nucleus, locus coeruleus and nucleus basalis Meynert contributes to pGlu-Aß pathology in Alzheimer's disease
}

\author{
Markus Morawski • Maike Hartlage-Rübsamen • Carsten Jäger • Alexander Waniek • \\ Stephan Schilling • Claudia Schwab • Patrick L. McGeer • Thomas Arendt • \\ Hans-Ulrich Demuth • Steffen Roßner
}

Received: 20 January 2010/Revised: 31 March 2010/ Accepted: 2 April 2010/Published online: 10 April 2010 (C) The Author(s) 2010. This article is published with open access at Springerlink.com

\begin{abstract}
Glutaminyl cyclase (QC) was discovered recently as the enzyme catalyzing the pyroglutamate (pGlu or $\mathrm{pE}$ ) modification of N-terminally truncated Alzheimer's disease $(\mathrm{AD}) \mathrm{A} \beta$ peptides in vivo. This modification confers resistance to proteolysis, rapid aggregation and neurotoxicity and can be prevented by QC inhibitors in vitro and in vivo, as shown in transgenic animal models. However, in mouse brain QC is only expressed by a relatively low proportion of neurons in most neocortical and hippocampal subregions. Here, we demonstrate that QC is highly abundant in subcortical brain nuclei severely affected in AD. In particular, QC is expressed by virtually all urocortin-1positive, but not by cholinergic neurons of the EdingerWestphal nucleus, by noradrenergic locus coeruleus and by cholinergic nucleus basalis magnocellularis neurons in
\end{abstract}

M. Morawski and M. Hartlage-Rübsamen contributed equally to this manuscript.

M. Morawski · M. Hartlage-Rübsamen · C. Jäger ·

A. Waniek $\cdot$ T. Arendt $\cdot$ S. Roßner $(\square)$

Paul Flechsig Institute for Brain Research, University of Leipzig,

Jahnallee 59, 04109 Leipzig, Germany

e-mail: steffen.rossner@medizin.uni-leipzig.de

S. Schilling · H.-U. Demuth

Probiodrug AG, Weinbergweg 22, Biocenter,

06120 Halle/Saale, Germany

C. Schwab · P. L. McGeer

Kinsmen Laboratory of Neurological Research,

Department of Psychiatry, University of British Columbia,

Vancouver, BC, Canada

H.-U. Demuth

Ingenium Pharmaceuticals GmbH, Fraunhoferstr. 13,

82152 Martinsried/Munich, Germany mouse brain. In human brain, QC is expressed by both, urocortin-1 and cholinergic Edinger-Westphal neurons and by locus coeruleus and nucleus basalis Meynert neurons. In brains from $\mathrm{AD}$ patients, these neuronal populations displayed intraneuronal $\mathrm{pE}-\mathrm{A} \beta$ immunoreactivity and morphological signs of degeneration as well as extracellular pE-A $\beta$ deposits. Adjacent AD brain structures lacking QC expression and brains from control subjects were devoid of such aggregates. This is the first demonstration of QC expression and $\mathrm{pE}-\mathrm{A} \beta$ formation in subcortical brain regions affected in $\mathrm{AD}$. Our results may explain the high vulnerability of defined subcortical neuronal populations and their central target areas in $\mathrm{AD}$ as a consequence of $\mathrm{QC}$ expression and $\mathrm{pE}-\mathrm{A} \beta$ formation.

Keywords Alzheimer's disease · Locus coeruleus · Edinger-Westphal nucleus - Nucleus basalis Meynert . Glutaminyl cyclase $\cdot$ Pyroglutamate-Abeta

$\begin{array}{ll}\text { Abbreviations } \\ \text { AD } & \text { Alzheimer's disease } \\ \text { APP } & \text { Amyloid precursor protein } \\ \text { CBF } & \text { Cholinergic basal forebrain } \\ \text { ChAT } & \text { Choline acetyltransferase } \\ \text { CRF } & \text { Corticotropin-releasing factor } \\ \text { DAB } & 3,3^{\prime} \text {-Diaminobenzidine } \\ \text { EWN } & \text { Edinger-Westphal nucleus } \\ \text { LC } & \text { Locus coeruleus } \\ \text { Nbm } & \text { Mouse nucleus basalis magnocellularis } \\ \text { NbM } & \text { Human nucleus basalis Meynert } \\ \text { pE-A } \beta & \text { Pyroglutamate-modified A } \beta \\ \text { QC } & \text { Glutaminyl cyclase } \\ \text { TH } & \text { Tyrosine hydroxylase } \\ \text { Ucn-1 } & \text { Urocortin-1 }\end{array}$




\section{Introduction}

The appearance of neurofibrillary tangles, loss of specific neuronal populations and deposits of $\mathrm{A} \beta$ peptides in neocortical brain structures are major histopathological hallmarks of Alzheimer's disease (AD) [60]. A $\beta$ peptides are liberated from the amyloid precursor protein (APP) after sequential enzymatic action of $\beta$ - and $\gamma$-secretases. The $\gamma$-secretase cleavage results in the generation of $A \beta_{1-40}$ and $A \beta_{1-42}$ peptides, which exhibit different potencies of aggregation, fibril formation and neurotoxicity $[17,23,24,44,62]$. Additionally, N-terminally truncated $\mathrm{A} \beta$ peptides displaying an $\mathrm{N}$-terminal glutamate residue are abundant in brains from AD patients $[29,46,51,61$, 64]. A substantial proportion of these $\mathrm{N}$-truncated $\mathrm{A} \beta$ peptides undergoes subsequent cyclization of $\mathrm{N}$-terminal glutamate (E) into pyroglutamate (pE) [50, 51]. The resulting $\mathrm{pE}-\mathrm{A} \beta$ peptides have been shown to be a major constituent of $\mathrm{A} \beta$ deposits in sporadic and familial $\mathrm{AD}$ $[38,43,50,73]$. Thus, the assumption has been made that $\mathrm{pE}-\mathrm{A} \beta$ peptides could play a prominent role in $\mathrm{AD}$ pathogenesis.

This view is supported by a number of experimental observations. For example, a particular neurotoxicity of $\mathrm{pE}-\mathrm{A} \beta$ peptides in primary neurons, neuronal cell lines and transgenic animals has been demonstrated [1, 47, 72]. Moreover, $\mathrm{pE}$-modification of $\mathrm{N}$-truncated $\mathrm{A} \beta$ peptides is believed to have a significant influence on plaque generation and clearance. So it has been shown that the cyclization of glutamate into $\mathrm{pE}$ leads to a loss of $\mathrm{N}$-terminal charge resulting in accelerated aggregation of pE-A $\beta$ when compared with unmodified $\mathrm{A} \beta$ peptides $[19$, 47] and that $\mathrm{pE}-\mathrm{A} \beta$ acts as a seed for aggregation as well as for co-aggregation of non-modified $\mathrm{A} \beta$ peptides [12, $36,53,56]$. Furthermore, cyclization of $\mathrm{N}$-terminal glutamate of $\mathrm{A} \beta$ peptides confers resistance to degradation by most aminopeptidases as well as $\mathrm{A} \beta$-degrading endopeptidases [49].

However, for a long time, the molecular pathway leading to $\mathrm{N}$-terminal glutamate cyclization of truncated $\mathrm{A} \beta$ peptides remained elusive. Recently, glutaminyl cyclase (QC) has been shown to be the enzyme catalyzing $\mathrm{pE}-\mathrm{A} \beta$ peptide generation in vitro [52] and in vivo [11, 54, 55]. Chronic inhibition of QC in transgenic mouse models of $\mathrm{AD}$ resulted in reduced $\mathrm{pE}-\mathrm{A} \beta$ peptide generation and in diminished total $\mathrm{A} \beta$ peptide concentrations [54]. Thus, the enzymatic activity of QC appears to be a prerequisite for pE-A $\beta$ peptide generation and, therefore, QC-expressing neurons may be at special risk for degeneration. In a recent study focussing on QC expression in telencephalic and diencephalic mouse brain regions, we observed $\mathrm{QC}$ in a subpopulation of lateral and paraventricular hypothalamic neurons and in a moderate number of GABAergic interneurons in the hippocampal molecular layer, in the hilus of the dentate gyrus and in all layers of the neocortex [18]. However, the proportion of QC neurons in cortex and hippocampus displaying pronounced immunoreactivity was rather low $(0.5-2 \%)$, which may explain the lack of substantial neurodegeneration in these brain structures in APP transgenic mouse models. On the other hand, even the degeneration of a small number of GABAergic interneurons in the hippocampus may have perturbing effects on long-term potentiation and on the performance in learning/ memory tests [66].

In $\mathrm{AD}$, in addition to neocortical and hippocampal neurodegeneration and $A \beta$ plaque pathology, there is a selective loss of defined neuronal populations in distinct subcortical brain nuclei, including the nucleus basalis Meynert $(\mathrm{NbM})$ of the cholinergic basal forebrain [2, 9, 70], the Edinger-Westphal nucleus (EWN) [21, 45, 58, 59] and the locus coeruleus (LC) $[5,6,16,32,67]$. Therefore, we asked whether QC may be expressed by neurons of these nuclei and, if so, whether it may contribute to $\mathrm{pE}-\mathrm{A} \beta$ pathology.

\section{Materials and methods}

\section{Experimental animals}

Wild type C57B16 mice and QC knock-out mice aged 2-3 months ( $N=4$ each) were used for the immunohistochemical analysis of QC expression in EWN, LC and $\mathrm{Nbm}$. QC knock-out mice were generated on the basis of a classical homologous recombination approach. Cre-mediated excision of exons 5 and 6 was confirmed by PCR and RT-PCR. The constitutive deletion of these exons resulted in an additional frame shift and thus in a complete loss of the C-terminal part of the protein (not shown).

Preparation of mouse brain samples

for immunohistochemistry

Mice were anaesthetised with pentobarbital and perfused transcardially with $25 \mathrm{ml}$ phosphate-buffered saline (PBS $0.01 \mathrm{M}, \mathrm{pH} 7.4$ ) followed by perfusion with $25 \mathrm{ml} 4 \%$ paraformaldehyde in phosphate buffer (PB $0.1 \mathrm{M}, \mathrm{pH}$ 7.4). The brains were removed from the skull and postfixed by immersion in the same fixative overnight at $4^{\circ} \mathrm{C}$. After cryoprotection in $30 \%$ sucrose in $0.1 \mathrm{M} \mathrm{PB}$ for 3 days, the brains were snap-frozen in $n$-hexane at $-68^{\circ} \mathrm{C}$ and stored at $-20^{\circ} \mathrm{C}$. Coronal sections $(30 \mu \mathrm{m})$ were cut on a sliding microtome and collected in $0.1 \mathrm{M}$ PB. 
Human brain tissue

\section{Tissue preparation}

Fifteen mm-thick tissue blocks were prepared in the frontal plane according to the atlas of the human brain [31] and fixed in $4 \%$ paraformaldehyde for 3-4 days. Areas containing the regions of interest were cryoprotected in $30 \%$ sucrose in $0.1 \mathrm{M}$ PBS, pH 7.4. Series of $30 \mu \mathrm{m}$-thick sections were cut on a freezing microtome and collected in PBS containing $0.1 \%$ sodium azide.

\section{Identification of anatomical regions and applied nomenclature}

Anatomical regions were identified using Nissl-stained sections and the atlas of the human brain [31]. The nomenclature of brain regions was mainly adopted from atlases of human brain [31], human brainstem [42] and rhesus monkey brain [41]. We additionally used the data of detailed anatomical descriptions of the EWN [21, 22], the LC $[33,34]$ and the NbM [2].

\section{Characterization of human brain tissue}

The EWN, LC and NbM were evaluated for QC expression and for $\mathrm{pE}-\mathrm{A} \beta$ deposition in brains from eight $\mathrm{AD}$ cases and from eight age-matched control subjects (Table 1). The definite diagnosis of $\mathrm{AD}$ for all cases used in this study was based on the presence of neurofibrillary tangles and neuritic plaques in the hippocampal formation and neocortical areas and met the criteria of the National Institute of Neurologic and Communicative Disorders and Stroke and the Alzheimer's Disease and Related Disorders Association [37]. Brain tissue containing the EWN (Talairach space 28-29 mm) according to [31], the LC (Obex 20-32) according to [42] and the $\mathrm{NbM}(\mathrm{Ch} 4$; Talairach space -2 to $-0.6 \mathrm{~mm}$ ) according to $[2,31]$ from the same cases was used for immunohistochemistry to detect the presence of $\mathrm{QC}, \mathrm{pE}-\mathrm{A} \beta$ and neuronal markers. Case recruitment and autopsy were performed in accordance with guidelines set by the Ethical Committees of the University of British Columbia and the Leipzig University (License\# 063/2000). The required consent was obtained for all cases.

\section{Immunohistochemistry for QC, Ucn-1, ChAT, TH} and $\mathrm{pE}-\mathrm{A} \beta$

All immunohistochemical procedures were performed on free-floating brain sections. Immunohistochemistry in human brain to detect QC was performed using the rabbit antiserum 1301 (1:500), which was raised against recombinant full length mouse QC expressed in yeast.
The polyclonal antiserum was purified using a HiTrap rProtein A FF prepacked column (5 ml, GE Healthcare) and antibody elution by a shift to $\mathrm{pH} 3$ using a citric acid buffer. The neutralised protein solution was stored at $-20^{\circ} \mathrm{C}$ after addition of $50 \%$ glycerol. The antibody showed no significant differences in detecting mouse, rat and human QC in western blot analysis and immunohistochemistry, which appears conceivable considering a $85 \%$ protein sequence identity. Moreover, the specificity of the QC antiserum was previously shown by the robust labelling of mouse hypothalamic neurons, a known source of QC and of peptide hormones modified by $\mathrm{QC}$, and by the absence of this labelling in brains from QC knock-out mice [18]. Additionally, the specificity of QC immunolabelling was validated by similar staining patterns obtained using a commercially available mouse anti-human QC antiserum (Abnova 1:500). On consecutive human brain sections, the neuronal markers urocortin-1 (Ucn-1), choline acetyltransferase (ChAT) and tyrosine hydroxylase (TH) as well as $\mathrm{pE}-\mathrm{A} \beta$ were detected using the following antisera: goat anti-Ucn-1 (St. Cruz 1:200), goat anti-ChAT (Millipore 1:500), mouse anti-TH (Millipore 1:500) and mouse antipE-A $\beta$ (Synaptic Systems 1:200). All sections were pretreated with an initial antigen retrieval step by heating to $90^{\circ} \mathrm{C}$ in $0.1 \mathrm{M}$ citrate buffer, $\mathrm{pH} 2.5$, for 3 min followed by rinsing with PBS-T. Brain sections were further treated with $60 \%$ methanol, $2 \% \mathrm{H}_{2} \mathrm{O}_{2}$ for $1 \mathrm{~h}$ prior to incubation with the primary antibodies at $4^{\circ} \mathrm{C}$ overnight in a humid chamber. The following day sections were incubated with secondary biotinylated donkey anti-rabbit, donkey antimouse or donkey anti-goat antibodies (Dianova 1:1,000) for $60 \mathrm{~min}$ at room temperature followed by the $\mathrm{ABC}$ method, which comprised incubation with complexed streptavidin-biotinylated horseradish peroxidase. Incubations were separated by washing steps ( 3 times $5 \mathrm{~min}$ in PBS-T). Binding of peroxidase was visualised by incubation with $2 \mathrm{mg}$ 3,3'-diaminobenzidine (DAB), $20 \mathrm{mg}$ nickel ammonium sulphate and $2.5 \mu \mathrm{H}_{2} \mathrm{O}_{2}$ per $5 \mathrm{ml}$ Tris buffer $(0.05 \mathrm{M}, \mathrm{pH}$ 8.0) for 1-2 min. The enzymatic reaction resulted in black labelling, which was well distinguishable from the brown neuropigment present in many human LC neurons.

Immunohistochemistry in brains from wild type and QC knock-out mice was performed similarly but developed by incubation with $4 \mathrm{mg}$ DAB and $2.5 \mu \mathrm{H}_{2} \mathrm{O}_{2}$ per $5 \mathrm{ml}$ Tris buffer $(0.05 \mathrm{M}, \mathrm{pH} 7.6)$ for $1-2 \mathrm{~min}$ resulting in a brown reaction product [18]. In control experiments, primary antibodies were omitted, resulting in absence of staining.

Double immunofluorescent labelling procedures

In order to relate $\mathrm{QC}$ expression in mouse brain to marker proteins of defined neuronal populations, double 
Table 1 Human brain tissue used for QC and $\mathrm{pE}-\mathrm{A} \beta$ labellings
$A D$ Alzheimer's disease, $P M D$ postmortem delay, $C O D$ cause of death, $E C$ entorhinal cortex

\begin{tabular}{|c|c|c|c|c|c|c|}
\hline Case \# & $\begin{array}{l}\text { PMD } \\
\text { (h) }\end{array}$ & Gender & $\begin{array}{l}\text { Age } \\
\text { (years) }\end{array}$ & $\begin{array}{l}\text { Brain } \\
\text { weight }(\mathrm{g})\end{array}$ & COD & $\begin{array}{l}\text { Braak } \\
\text { staging }\end{array}$ \\
\hline \multicolumn{7}{|l|}{ Control } \\
\hline 1 & 48 & Female & 75 & 1,130 & Cardial infarction & 0 \\
\hline 2 & 72 & Female & 68 & 1,284 & Bronchopneumonia & 0 \\
\hline 3 & 24 & Female & 82 & 1,180 & Ovarian cancer & 0 \\
\hline 4 & 48 & Male & 78 & 1,420 & Cardial infarction & 0 \\
\hline 5 & 9 & Female & 43 & n.a. & Drug overd. (insulin) & 0 \\
\hline 6 & 24 & Female & 80 & 1,190 & Lung cancer & 0 \\
\hline 7 & 25 & Female & 75 & 1,234 & Lung cancer & 0 \\
\hline 8 & 7 & Male & 78 & 1,394 & Pulmonary failure & 0 \\
\hline Mean & 32.1 & $6 / 2$ & 72.4 & & & \\
\hline \multicolumn{7}{|l|}{$\mathrm{AD}$} \\
\hline 1 & 55 & Female & 95 & 1,060 & Cardial infarction & VI \\
\hline 2 & 32 & Female & 70 & 1,200 & Respiratory failure & IV \\
\hline 3 & 28 & Male & 68 & 960 & Bronchopneumonia & VI \\
\hline 4 & 6 & Female & 58 & 1,010 & Respiratory failure & IV \\
\hline 5 & 16 & Female & 65 & 1,080 & Respiratory failure & $\mathrm{V}$ \\
\hline 6 & 40 & Female & 79 & 1,006 & n.a. & IV \\
\hline 7 & 24 & Male & 69 & 934 & n.a. & V \\
\hline 8 & 42 & Female & 91 & 1,230 & Stroke & IV \\
\hline Mean & 30.4 & $6 / 2$ & 74.4 & & & \\
\hline
\end{tabular}

immunofluorescent labellings were performed using rabbit anti-QC antiserum 1301 (1:250) combined with goat antiUcn-1 (1:100), goat anti-ChAT (1:250) and mouse anti-TH (1:250), respectively. Brain sections were incubated with cocktails of primary antibodies overnight at $4^{\circ} \mathrm{C}$. The following day, sections were washed three times with TBS and were then incubated with appropriate cocktails of secondary antibodies (i.e. biotinylated donkey or goat antirabbit; 1:400 and Cy3-conjugated goat anti-mouse or donkey anti-goat, 1:200 Dianova) for $60 \mathrm{~min}$ at room temperature. After washing, brain sections were incubated with streptavidin-Cy2 conjugates (Dianova 1:100) for $45 \mathrm{~min}$, washed again and mounted onto gelatine-coated slides. In double immunofluorescent labellings, the omission of one primary antibody resulted in the depletion of the corresponding fluorescent signal without affecting the detection of the second antigen.

\section{Microscopy}

\section{Light microscopy}

Tissue sections were examined with a Zeiss Axiovert $200 \mathrm{M}$ microscope equipped with a motorised stage (Märzhäuser, Germany) with MosaiX software and by means of a CCD camera (Zeiss MRC) connected to an Axiovision 4.6 image analysis system (Zeiss, Germany).

\section{Confocal laser scanning microscopy}

Laser scanning microscopy (LSM 510, Zeiss, Oberkochen, Germany) was performed to reveal co-localization of QC with TH, Ucn-1 and ChAT in LC, EWN and Nbm, respectively. For Cy2-labelled QC (green fluorescence), an argon laser with $488 \mathrm{~nm}$ excitation was used and emission from Cy 2 was recorded at $510 \mathrm{~nm}$ applying a low-range band pass (505-550 nm). For Cy3-labelled TH, Ucn-1 and ChAT (red fluorescence), a helium-neon laser with $543 \mathrm{~nm}$ excitation was applied and emission from Cy3 at $570 \mathrm{~nm}$ was detected applying high-range band pass (560-615 nm).

Photoshop CS2 (Adobe Systems, Mountain View, CA, USA) was used to process the images obtained by light and confocal laser scanning microscopy with minimal alterations to brightness, sharpness, colour saturation and contrast.

Quantification of QC-immunoreactive neurons and $\mathrm{pE}-\mathrm{A} \beta$ deposits

Quantitative analysis of ChAT-, Ucn-1-, TH- and QCimmunoreactive neurons and $\mathrm{pE}-\mathrm{A} \beta$ deposits present in EWN, LC and human NbM was performed following the procedure described in [13]. Noradrenergic LC neurons in stained sections were additionally identified by the content of neuromelanin. Neurons were counted when the soma 
and at least one dendrite could be identified. The outline of EWN, LC and NbM and the location of neurons inside these nuclei were assessed by means of a Stereoinvestigator (Microbrightfield, Williston, VT, USA; including a Zeiss Axioskop 2 plus, Märzhäuser micropositioning system and a Ludl 5000 controller) with the Neurolucida software. QC expression in EWN, LC and NbM was investigated in three sections from rostral to caudal (largely comprising the whole nucleus) in all cases. In sections analysed, the number of neurons labelled for the neuronal marker (e.g. ChAT, TH or Ucn-1) in each brain region of control brain was set to $100 \%$. The relative numbers of $\mathrm{QC}$-immunoreactive neurons and $\mathrm{pE}-\mathrm{A} \beta$ deposits in brain regions analysed was calculated using the formula of Konigsmark [27].

\section{Results}

\section{Distinct QC expression in the mouse EWN}

First, QC immunohistochemistry was performed on mouse coronal midbrain sections at the level of bregma -3.1 to $-3.8 \mathrm{~mm}$. In the subcortical part of these sections, we only observed modest QC immunoreactivity in a relatively low percentage of neurons of some neuronal populations including substantia nigra and ventral tegmental area (not shown). In contrast, there was a small but robustly QCexpressing assembly of neurons within the EWN (Fig. 1). Labelling was absent from QC knock-out mouse brain sections, demonstrating the specificity of the immunohistochemical QC detection (Fig. 1). Since the EWN is known to be composed of a preganglionic cholinergic portion and a non-preganglionic, Ucn-1-positive part, we sought to identify the neuronal subpopulation expressing QC in this structure. Double immunofluorescent labellings revealed that QC is co-localised with Ucn-1 (Fig. 1) but not with ChAT (not shown) in neurons of the mouse EWN. Thus, QC-expressing neurons in the EWN represent the nonpreganglionic, Ucn-1-positive part of this nucleus in mouse brain.

Distinct QC expression in the mouse locus coeruleus

In order to extend these findings and to substantiate a possible function of $\mathrm{QC}$ in $\mathrm{pE}-\mathrm{A} \beta$ generation in vivo, we studied LC, a brainstem nucleus known to be severely affected in $\mathrm{AD}$. As in the case of the EWN, there was strong and spatially defined QC labelling of neurons in the $\mathrm{LC}$ region of mouse brain (Fig. 2). This labelling was absent in brain sections from QC knock-out mice (Fig. 2). In order to clearly identify these neurons, immunofluorescent double labelling of QC and TH was performed. QC was found to be strictly co-localised to TH, demonstrating co-expression by mouse noradrenergic LC neurons (Fig. 2).

Distinct QC expression in the mouse nucleus basalis magnocellularis

In contrast to the robust QC expression by almost all mouse Ucn-1-positive EWN and TH-positive LC neurons, the mouse Nbm contained relatively few QC-immunoreactive neurons (Fig. 3). Double labelling with the cholinergic marker enzyme ChAT in this brain region revealed that approximately $50 \%$ of mouse Nbm cholinergic neurons coexpressed QC (Fig. 3).

It is important to note that in brains from QC knock-out mice, the neuronal marker proteins Ucn-1, TH and ChAT were detected in EWN, LC and Nbm neurons, respectively. This indicates survival of these neuronal populations in the absence of QC expression.

\section{Distinct QC expression in human EWN, LC and NbM}

We then asked whether QC is also expressed in the corresponding subcortical nuclei of human brain and whether $\mathrm{pE}-\mathrm{A} \beta$ formation spatially correlates with $\mathrm{QC}$ expression in $\mathrm{AD}$ brains. Immunohistochemical labelling of human midbrain sections cut at the level of the EWN revealed a distinct and robust QC expression in this brain structure (Fig. 4), confirming observations made in mouse brain. In adjacent brain sections, two marker proteins of neuronal subpopulations of the EWN-Ucn-1 and ChAT-were visualised. In contrast to the mouse brain, the cholinergic part of this nucleus was much larger in relative size in human brain and contained more neurons when compared with the Ucn-1-positive portion (Fig. 4). Interestingly, QC expression was not limited to the Ucn-1-positive portion of the human EWN, but was also present in the cholinergic part of this brain structure (Fig. 4). This finding differs from the observations made in mice, where QC expression in the EWN was restricted to Ucn-1-positive neurons. Neurons in adjacent brain structures outside the EWN and perioculomotor area, such as red nucleus and superior colliculus did not display QC immunoreactivity.

Since we observed QC expression in mouse LC and because of the well-documented LC pathology in $\mathrm{AD}$, we also examined human brainstem sections containing this structure. In similarity to observations made in mouse brain, QC was also found to be expressed by noradrenergic neurons in human LC (Fig. 4). The identity of QC-immunoreactive neurons as noradrenergic LC neurons was demonstrated by the typical neuronal pigment and by the expression of $\mathrm{TH}$ in consecutive brain sections. Interestingly, QC immunoreactivity was not limited to LC 
Fig. 1 QC expression in mouse Edinger-Westphal nucleus. Top row QC immunoreactivity is absent from midbrain sections of QC knock-out mice as shown at increasing magnifications from left to right. In contrast, there is a specific and robust labelling of a neuronal population in the EWN of wild type mice (middle row). Since the EWN is known to contain both, Ucn-1 and ChAT neurons, double labellings were performed. QC (green fluorescence) was found to be co-localised with Ucn-1 (red fluorescence; bottom row), but not with ChAT (not shown)
Fig. 2 QC expression in mouse locus coeruleus. Top row QC immunoreactivity is absent from brainstem sections of QC knock-out mice as shown at increasing magnifications from left to right. In contrast, there is a specific and robust QC labelling of a neuronal population corresponding to the LC of wild type mice (middle row). In order to identify these neurons as noradrenergic LC neurons, double labellings were performed. There was an almost complete overlap of QC (green) and TH (red) immunoreactivity in the mouse LC (bottom row)

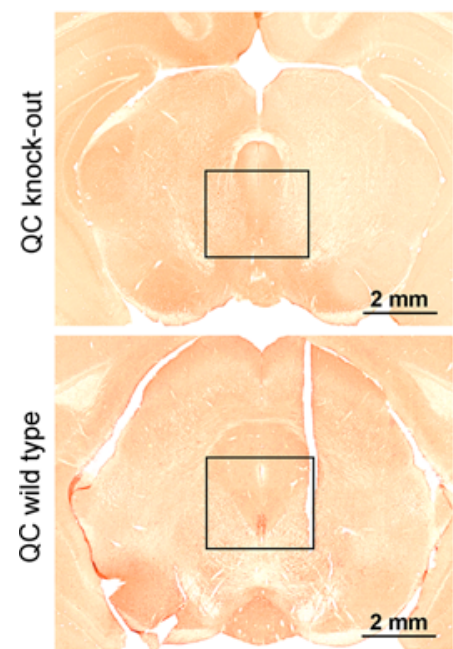

QC expression in mouse EWN
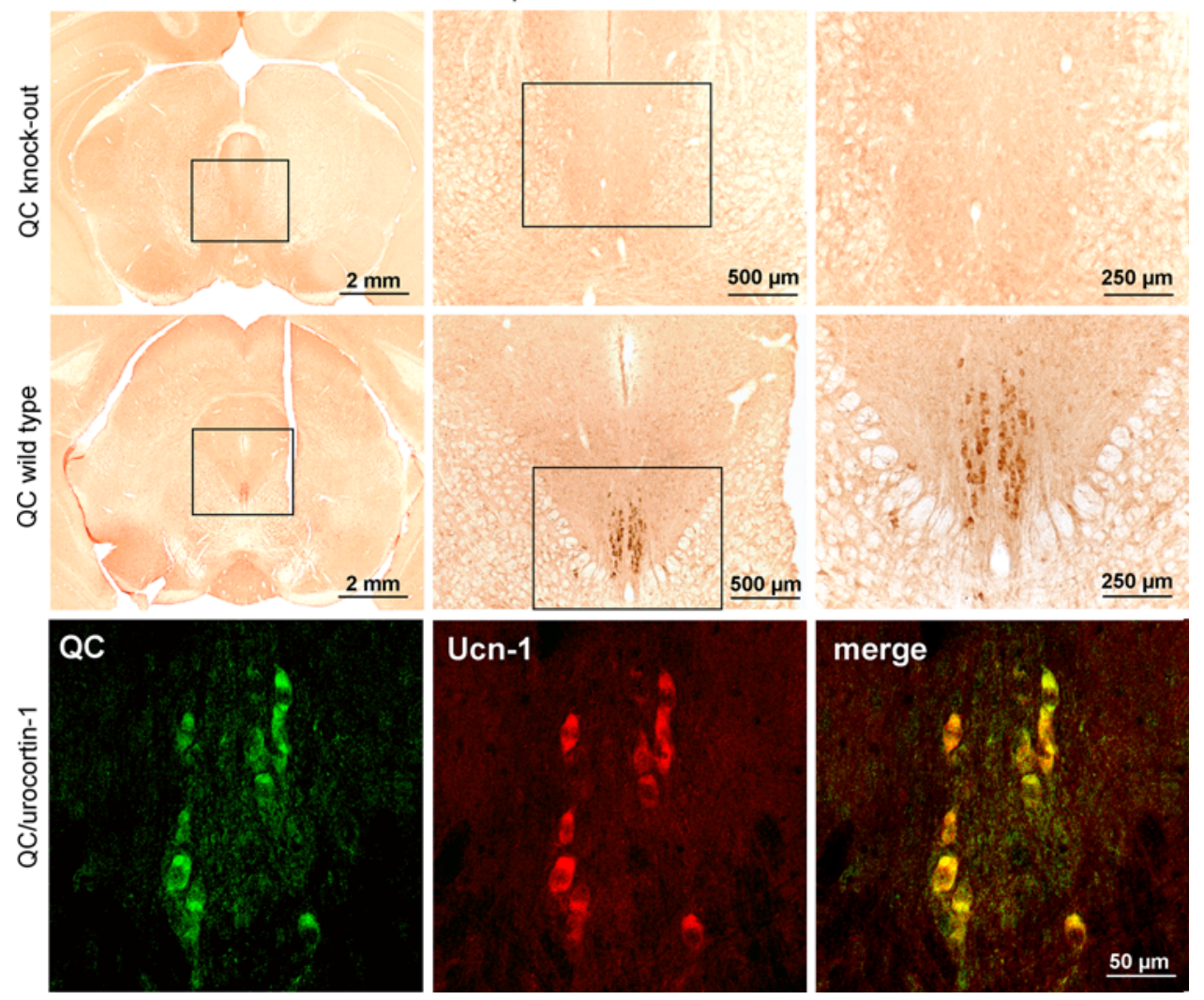

QC expression in mouse LC
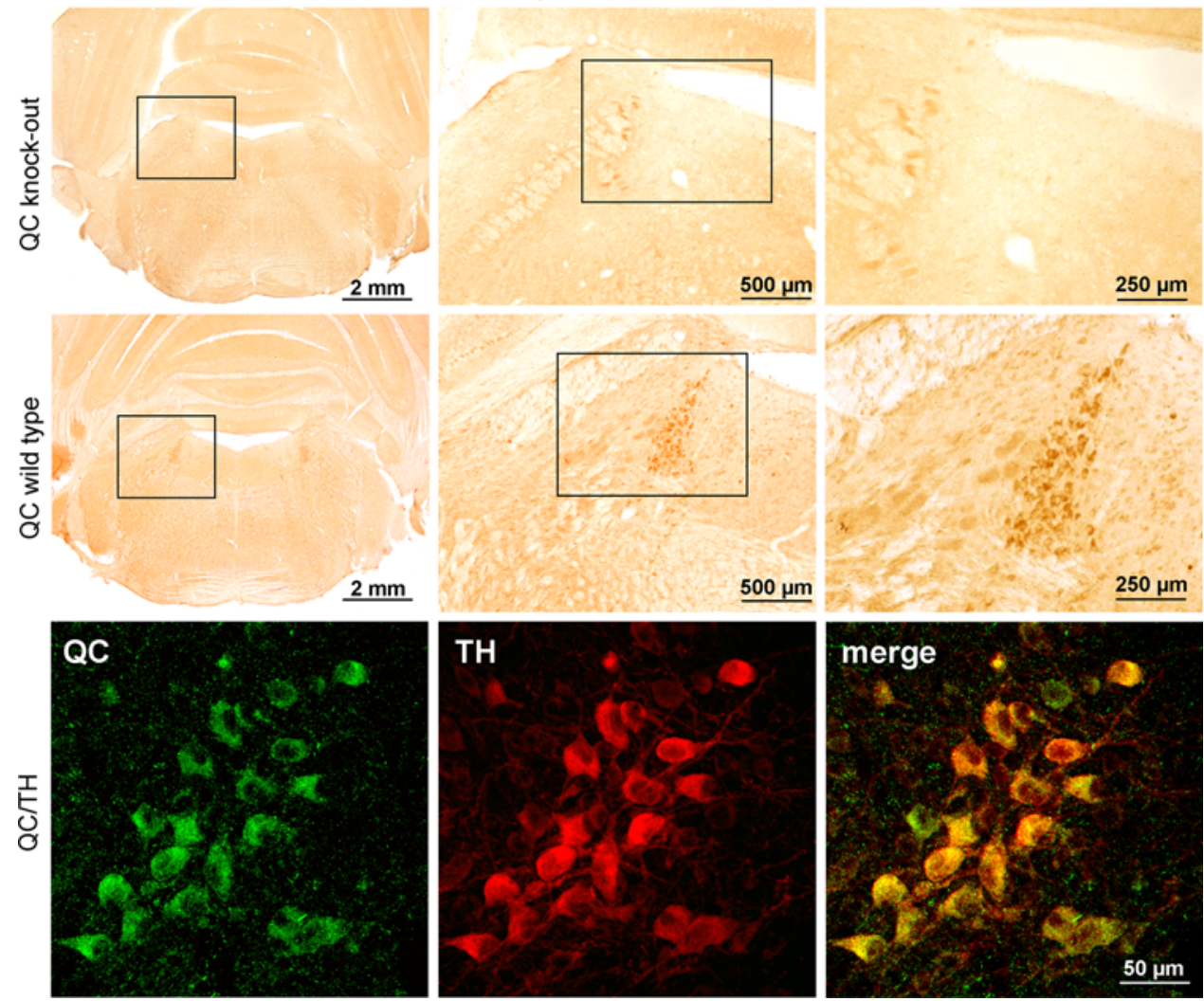
Fig. 3 QC expression in mouse nucleus basalis magnocellularis. Top row QC immunoreactivity is absent from basal forebrain sections of QC knock-out mice as shown at increasing magnifications from left to right. In contrast, there is a specific QC labelling of a neuronal population corresponding to the nucleus basalis of wild type mice (middle row). In order to identify these neurons as cholinergic basal forebrain neurons, double labellings were performed. QC (green) was found to be co-expressed by a proportion of ChAT-

immunoreactive (red) neurons in the mouse nucleus basalis (bottom row). Double-labelled neurons are indicated by yellow colour in the overlay channel and by arrows

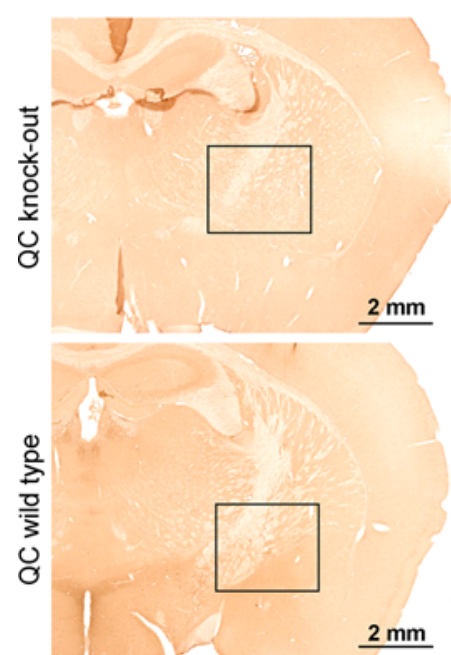

QC expression in mouse $\mathrm{Nbm}$

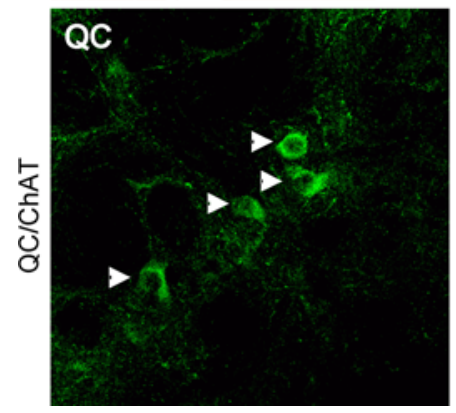

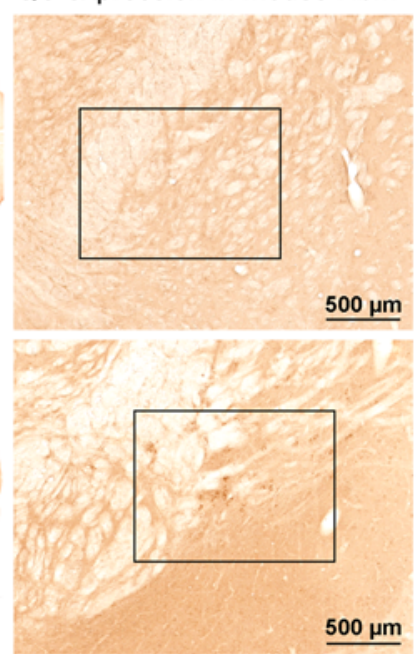
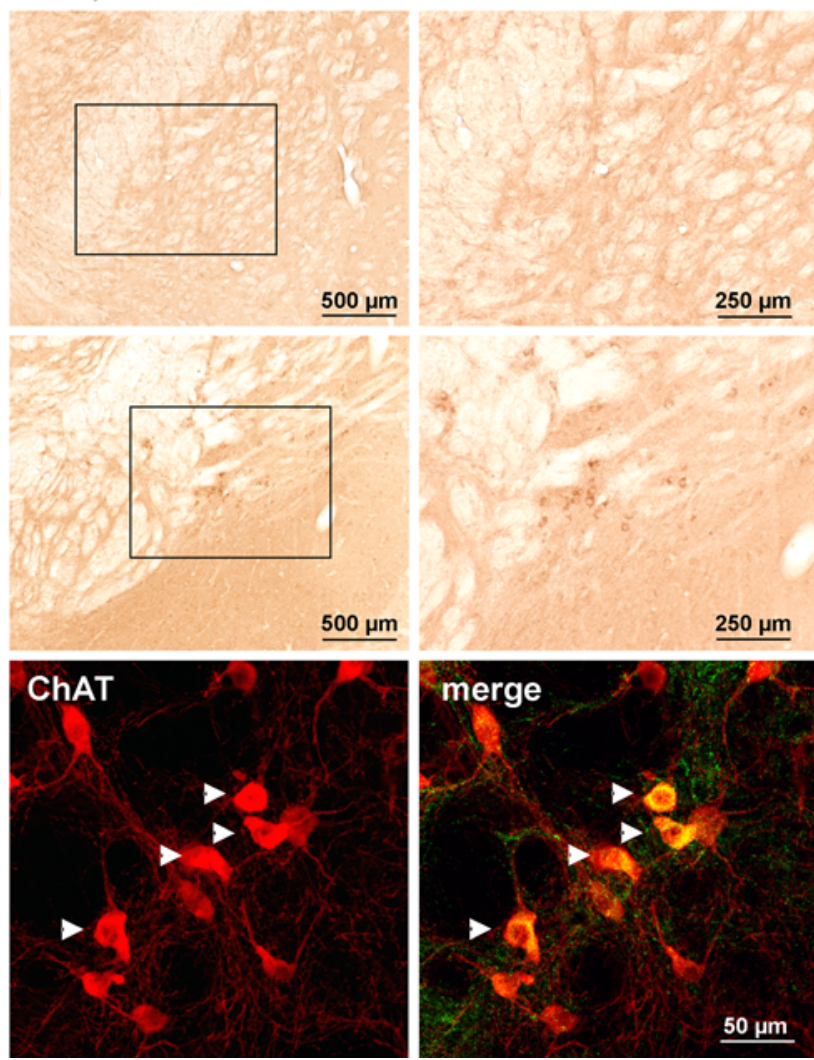
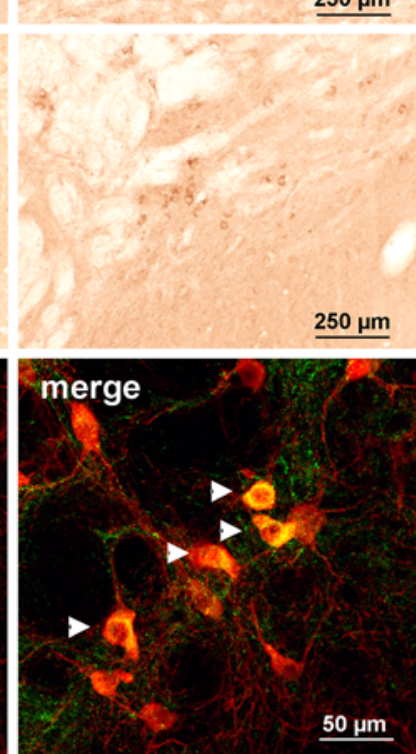

neuronal somata but was also detected in TH-positive fibres.

Although only a sub-population of cholinergic $\mathrm{Nbm}$ neurons in mouse brain contained QC, the analysis of human brain sections revealed strong QC expression by virtually all NbM neurons (Fig. 4). The intracellular pattern of QC immunoreactivity in the neuronal somata and processes was similar to that detected in EWN and LC.

Intraneuronal and extracellular $\mathrm{pE}-\mathrm{A} \beta$ aggregates in the Alzheimer's disease EWN, LC and $\mathrm{NbM}$

Given the high level of QC expression in human EWN, LC and $\mathrm{NbM}$ and the role of $\mathrm{QC}$ in $\mathrm{pE}-\mathrm{A} \beta$ formation, we asked whether there is $\mathrm{pE}-\mathrm{A} \beta$ plaque pathology in these human brain nuclei from AD patients. Using a mouse monoclonal antibody raised against $\mathrm{pE}-\mathrm{A} \beta$, we observed focal plaque formation in both, the Ucn-1-positive and the cholinergic portion of EWN as well as in LC and NbM of AD brain (Fig. 5). Similar to the QC staining pattern, brain structures outside the EWN and perioculomotor area, such as red nucleus and superior colliculus did not display $\mathrm{pE}-\mathrm{A} \beta$ immunoreactivity. Additionally, we detected intraneuronal accumulation of $\mathrm{pE}-\mathrm{A} \beta$ in EWN, LC and $\mathrm{NbM}$ neurons in brain tissue from $\mathrm{AD}$ patients but only rarely in normal brain (Fig. 5).

Quantitative analysis of $\mathrm{QC}$ expression and $\mathrm{pE}-\mathrm{A} \beta$ deposit formation

In order to obtain quantitative data on the degree of QC expression and $\mathrm{pE}-\mathrm{A} \beta$ deposit formation in the subcortical nuclei analysed, the numbers of Ucn-1 and cholinergic EWN, TH-positive LC and cholinergic NbM neurons were determined and the proportion of QC-positive neurons was calculated for each structure. In the normal human brain, almost all $\mathrm{NbM}$ neurons and approximately $80 \%$ of LC neurons co-expressed QC, whereas in the EWN only $20 \%$ of neurons were found to be QC immunoreactive (Fig. 6). In brains from $\mathrm{AD}$ patients, neuronal numbers were reduced by 39,26 and $12 \%$ in NbM, LC and the Ucn-1 and cholinergic part of EWN, respectively (Fig. 6). Thus, the highest degree of neuronal loss was detected in the brain region with the most abundant $\mathrm{QC}$ expression. Additionally, a significant number of $\mathrm{pE}-\mathrm{A} \beta$ deposits was detected in $\mathrm{NbM}, \mathrm{LC}$ and EWN from AD patients but not from control subjects (Fig. 6). As in the case of neuronal loss, the most pronounced $\mathrm{pE}-\mathrm{A} \beta$ deposit formation was observed in NbM of AD subjects. 


\section{QC expression in human EWN}

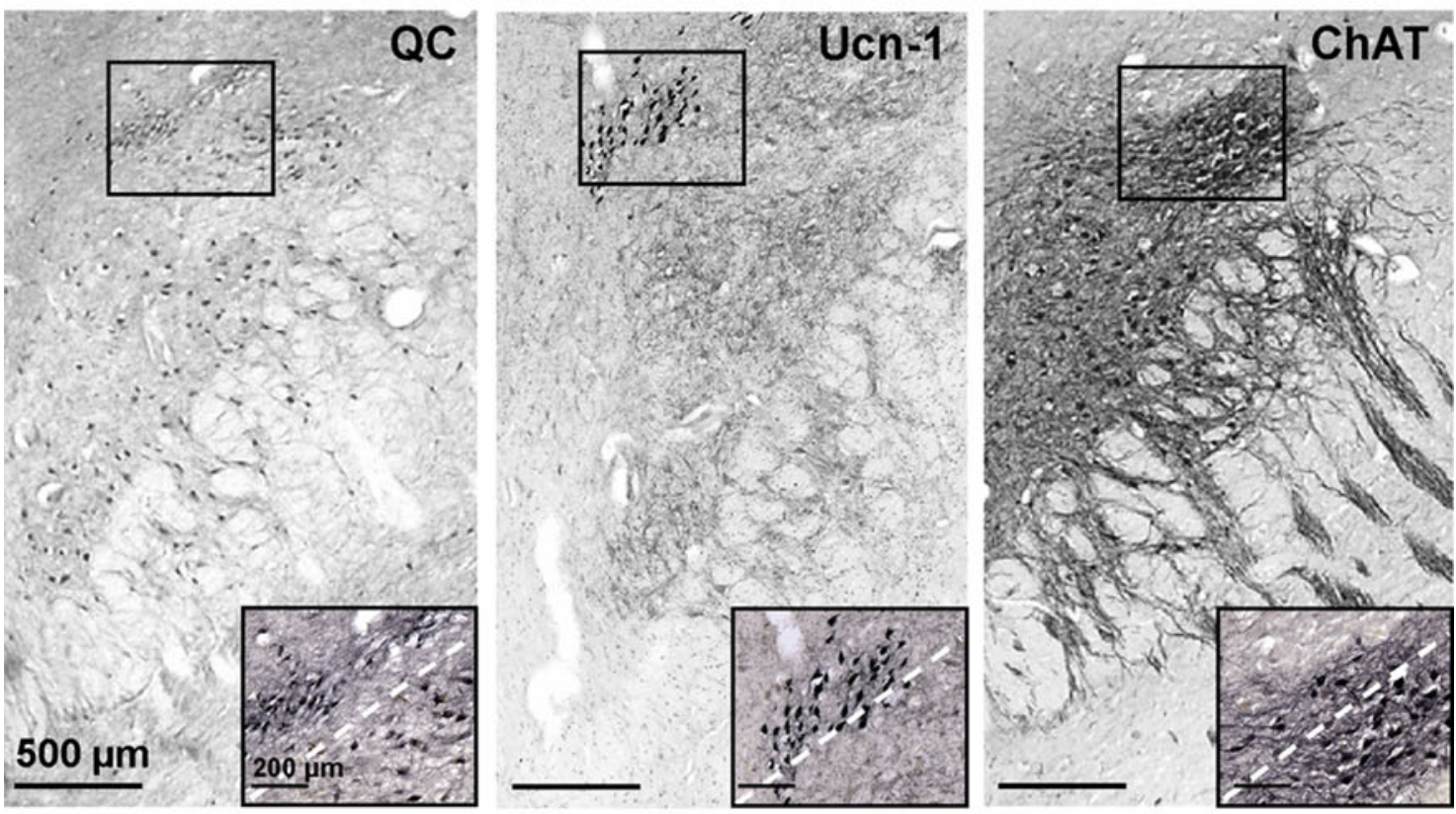

QC expression in human LC

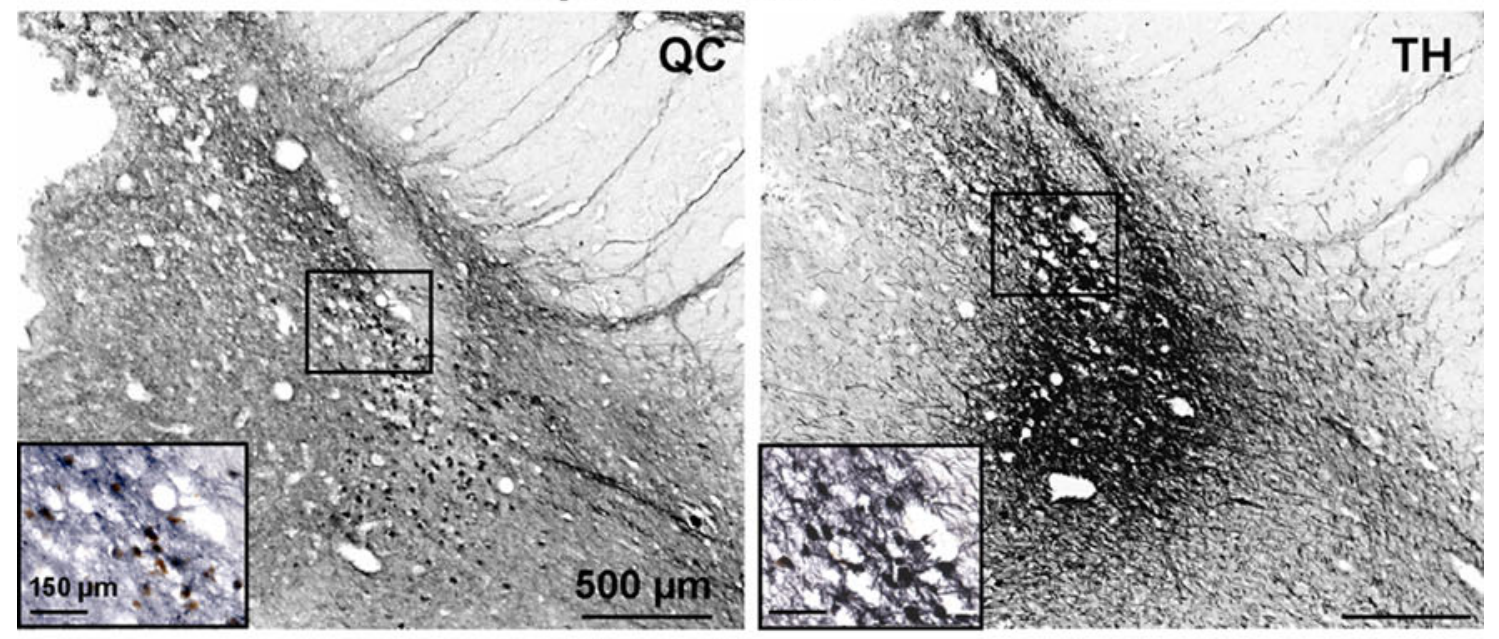

QC expression in human NbM

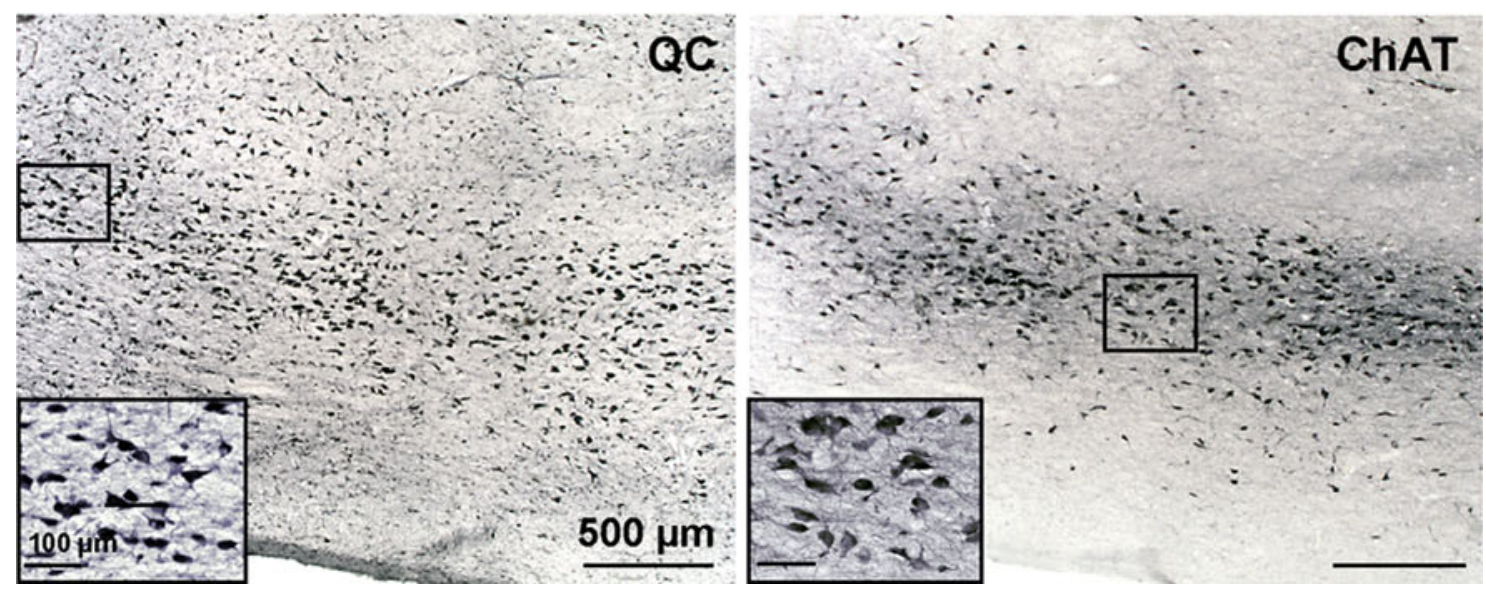


4 Fig. 4 QC expression in the human Edinger-Westphal nucleus, locus coeruleus and nucleus basalis Meynert. QC immunoreactivity was present in midbrain sections in a defined cell group (top left). These cells include both Ucn-1 and ChAT expressing subpopulations of the Edinger-Westphal nucleus as shown by the labelling of these marker proteins in adjacent brain sections. QC-immunoreactive neurons were also detected in brainstem sections in a small, defined cell group within the locus coeruleus area (middle left). Labelling of consecutive brain sections with TH identified these neurons as noradrenergic LC neurons (middle right). The highest density of QC-immunoreactive neurons was detected in the nucleus basalis Meynert (bottom left), which was identified by the presence of cholinergic $\mathrm{Ch} 4$ neurons (bottom right). Scale bars in overview $500 \mu \mathrm{m}$, in higher magnification inserts $100 \mu \mathrm{m}, 150 \mu \mathrm{m}$ and $200 \mu \mathrm{m}$ as indicated

\section{Discussion}

The aim of this study was to reveal whether QC expression and $\mathrm{pE}-\mathrm{A} \beta$ deposition can be spatially correlated with defined neuronal populations known to be affected by selective degeneration and by $\mathrm{A} \beta$ pathology in $\mathrm{AD}$ brains. For the initial screening of QC expression in the basal forebrain and brainstem, mice were used because of unrestricted access and the availability of QC knock-out mice as controls for the immunohistochemical QC labelling.
First, we demonstrated distinct QC expression by Ucn1-positive EWN neurons in mice. Ucn-1 is a neuropeptide of the corticotropin-releasing factor (CRF) family and binds to $\mathrm{CRF}$ receptors 1 and 2, to the latter with higher affinity than CRF itself [65]. Ucn-1 is known to play a role in the regulation of food intake [63], energy balance [10] and anxiety [39] and Ucn-1 neurons of the EWN in particular appear to be involved in stress response [15, 28, 69] and alcohol consumption [3]. Interestingly, in a number of publications, midbrain structures including the EWN have been reported to display $\mathrm{A} \beta$ and Tau histopathology in AD patients [21, 45, 58, 59]. However, a comparison of these histological data appears difficult since the term EWN comprises several functionally different cell groups (preganglionic and several non-preganglionic cell groups, the latter including Ucn-1 positive neurons) and attempts have only been made recently to provide a clear and welldefined nomenclature of the EWN in mouse [68] and human brain [21, 22, 48].

With regard to QC expression in the EWN complex, we observed remarkable differences between mouse and human brain. Most strikingly, QC expression was limited to Ucn-1-positive EWN neurons in mice but also present in preganglionic cholinergic EWN neurons in humans. The $p E-A \beta$ in $E W N$

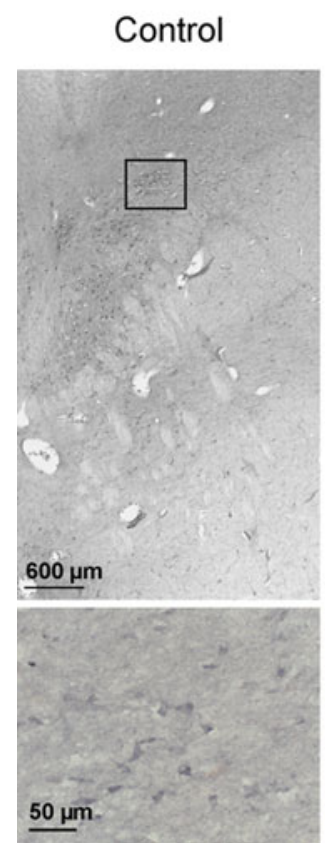

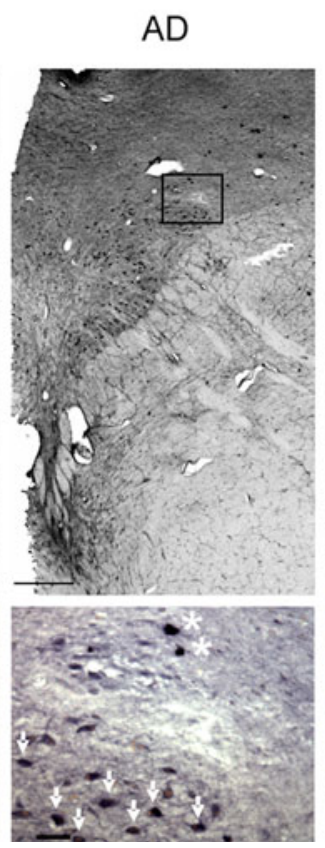

$p E-A \beta$ in LC

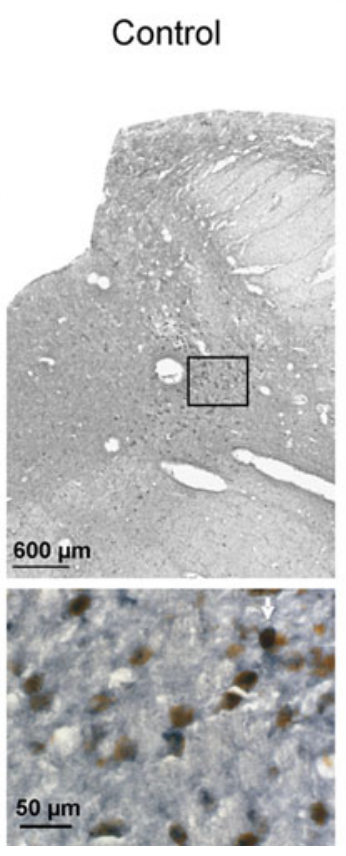

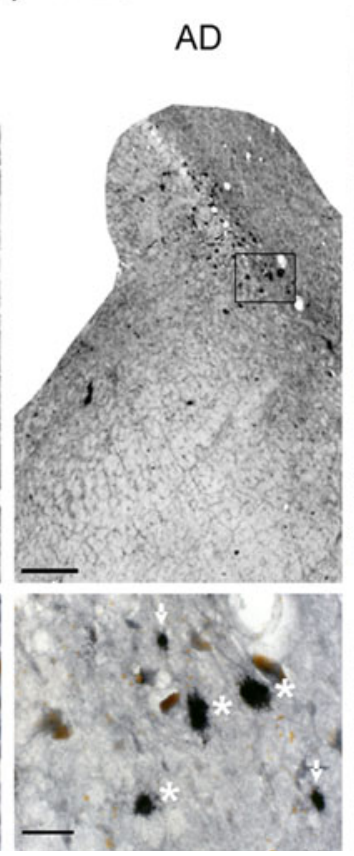

\section{$p E-A \beta$ in $\mathrm{NbM}$}

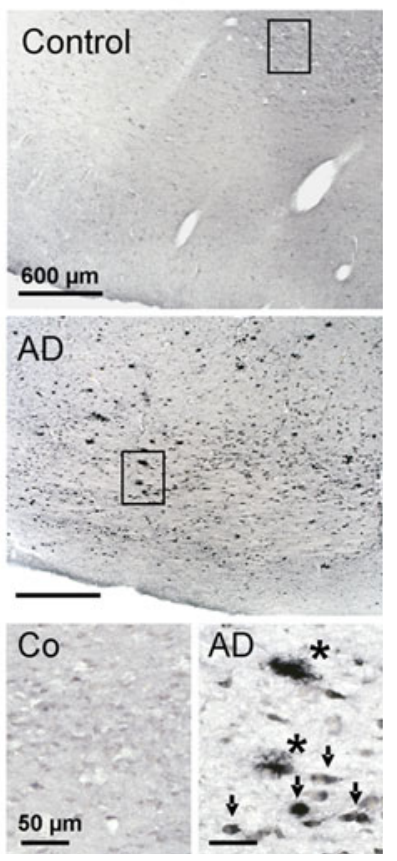

Fig. $5 \mathrm{pE}-\mathrm{A} \beta$ aggregates in human AD Edinger-Westphal nucleus, locus coeruleus and nucleus basalis Meynert. Left In the EWN of control subjects there was only a faint intraneuronal $\mathrm{pE}-\mathrm{A} \beta$ immunoreactivity. In contrast, in brains from AD patients the EWN was robustly labelled with intraneuronal $\mathrm{pE}-\mathrm{A} \beta$ (arrows) and $\mathrm{pE}-\mathrm{A} \beta$ plaques (asterisks). Middle In the LC of control subjects numerous neurons containing neuropigment (brown) but rarely intraneuronal
$\mathrm{pE}-\mathrm{A} \beta$ accumulations (arrow) and no $\mathrm{pE}-\mathrm{A} \beta$ deposits were present. In brains from $\mathrm{AD}$ patients there were intraneuronal $\mathrm{pE}-\mathrm{A} \beta$ accumulations (arrows) and $\mathrm{pE}-\mathrm{A} \beta$ immunoreactive plaques (asterisks). Right Intraneuronal $\mathrm{pE}-\mathrm{A} \beta$ (arrows) and $\mathrm{pE}-\mathrm{A} \beta$ deposits (asterisks) were detected in the $\mathrm{NbM}$ of $\mathrm{AD}$ patients but not in this brain region of control subjects. Scale bars in top row $600 \mu \mathrm{m}$, in bottom row $50 \mu \mathrm{m}$ 


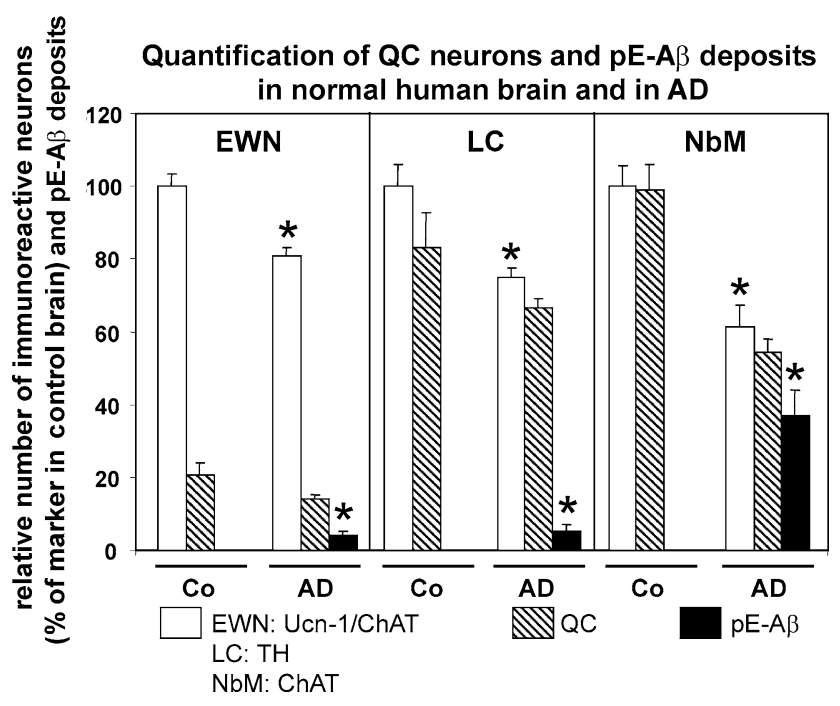

Fig. 6 Quantification of QC-expressing neurons and pE-A $\beta$ deposits in normal human brain and in $\mathrm{AD}$. The highest proportion of $\mathrm{QC}$ immunoreactive neurons in control subjects was detected in the NbM, followed by LC and EWN. In all brain regions analysed, there was a reduction of the neuronal number in $\mathrm{AD}$ as identified by expression of Ucn-1/ChAT, TH and ChAT, respectively $(* p<0.05)$. While in control subjects no $\mathrm{pE}-\mathrm{A} \beta$ deposits were detected in any of the brain nuclei investigated, a significant number of $\mathrm{pE}-\mathrm{A} \beta$ deposits was detected in $\mathrm{AD}$ brains. Both, neuronal loss and formation of $\mathrm{pE}-\mathrm{A} \beta$ deposits was most pronounced in $\mathrm{NbM}$

latter neuronal population has a function in adaptive pupillary reaction, which has been reported to be affected in $\mathrm{AD}$ patients in response to treatment with cholinergic antagonists [57]. Our demonstration of QC expression, $\mathrm{pE}$ $\mathrm{A} \beta$ formation and neurodegeneration in both Ucn-1 and cholinergic portions of EWN is in agreement with neuropathology in this nucleus observed earlier [45, 58, 59].

In addition to the EWN, we also demonstrated robust QC expression by a high proportion of noradrenergic LC neurons in mouse and human brain. LC degeneration is an early feature of $\mathrm{AD}$ pathology [14, 32]. The well-described noradrenergic neuronal loss [16] is accompanied by $A \beta$ and Tau pathology and correlates with $\mathrm{A} \beta$ plaque load, neurofibrillary tangle formation and the severity of dementia $[5,6,67$, 71]. However, since LC neurons are known to provide essential noradrenergic innervation to the hippocampal formation and neocortex [30], it is conceivable that secondary morphological and neurochemical changes also occur in these target regions. Indeed, elevated hippocampal acetylcholine and serotonin release as observed in mild cognitive impairment patients was also detected after specific lesions of noradrenergic LC neurons in experimental animals [25]. Moreover, noradrenaline deficiency has been shown to promote neocortical and hippocampal A $\beta$ pathology in transgenic animal models $[20,26]$. Additionally, there is evidence for the seeding of neuritic $A \beta$ plaques in target regions of brainstem neurons in $\mathrm{AD}$ [40].
This is also supported by the robust QC expression in human cholinergic $\mathrm{NbM}$ neurons. Interestingly, QC expression in the corresponding nucleus of mouse brain was less pronounced, a finding which might point towards a higher physiological relevance of $\mathrm{QC}$ expression in human $\mathrm{NbM}$ when compared with mouse Nbm neurons. In $\mathrm{AD}$, the degeneration of cholinergic $\mathrm{NbM}$ neurons is an early and consistent pathological feature and results in cholinergic denervation of the cortical mantle [2, 9, 70]. This neocortical cholinergic hypoactivity has been correlated to the degree of dementia and is targeted by cholinomimetic approaches in order to at least temporarily attenuate cognitive decline in $\mathrm{AD}$ patients [44]. As in the case of noradrenergic LC neurons, cholinergic $\mathrm{NbM}$ neurons innervate brain regions severely affected by $A \beta$ pathology and anterograde transport of $\mathrm{QC}$ and/or $\mathrm{pE}-\mathrm{A} \beta$ may contribute to neocortical $A \beta$ deposition. We thus believe that $\mathrm{QC}$ expression and subsequent $\mathrm{pE}-\mathrm{A} \beta$ formation may play a causative role in the specific deterioration of cholinergic $\mathrm{NbM}$ and noradrenergic LC neurons and, subsequently, in the alteration of neocortical and hippocampal function and in the seeding of neuritic plaques in AD.

In all human brain regions with high $\mathrm{QC}$ expression studied here, we detected intraneuronal $\mathrm{pE}-\mathrm{A} \beta$ and $\mathrm{pE}-\mathrm{A} \beta$ plaques in the brains from AD patients. The monoclonal pE-A $\beta$ antibody used in this study has been thoroughly characterised recently and was shown to detect $\mathrm{pE}-\mathrm{A} \beta$ aggregates in neocortical brain tissue from sporadic and familial AD cases [73]. The pE-A $\beta$ plaque load in $\mathrm{NbM}$, LC and EWN was comparable to that reported for total $A \beta$ deposits in these structures [2, 5, 45] and indicates that most, if not all, of these $\mathrm{A} \beta$ plaques contain $\mathrm{pE}$-modified $\mathrm{A} \beta$ peptides. Interestingly, the proportion of $\mathrm{QC}-\mathrm{immu}-$ noreactive neurons and numbers of $\mathrm{pE}-\mathrm{A} \beta$ deposits were highest in $\mathrm{NbM}$, which also displayed the most profound neuronal loss in $\mathrm{AD}$. In addition to the local formation of $\mathrm{pE}-\mathrm{A} \beta$ aggregates at sites of QC-immunoreactive somata, $\mathrm{pE}-\mathrm{A} \beta$ peptides may be released in target areas of projection neurons and may form $A \beta$ plaques in brain regions devoid of QC and/or APP expression. Such a phenomenon was recently demonstrated in APP/PS1 knock-in mice with neocortical and hippocampal, but not thalamical, transgene expression [8]. The authors first observed intraneuronal $A \beta$ in cortical neurons at 2 months of age, followed by extracellular cortical $\mathrm{A} \beta$ deposits at 6 months of age. In the thalamus of these mice, where no transgenic APP is expressed, extracellular $A \beta$ deposits were detected at 6 months of age without preceding intracellular $A \beta$ appearance. The authors concluded that $\mathrm{A} \beta$ may be deposited in brain regions where it is not produced via axonal transport and secretion from nerve terminals. Thus, in their animal model $A \beta$ is produced in neocortex and 
released from corticothalamic fibres in thalamus. In similarity to this scenario, our data suggest that $\mathrm{pE}-\mathrm{A} \beta$ generated by EWN, LC and NbM neurons may be released at neocortical and hippocampal target regions.

Taken together, the demonstration of robust and spatially restricted $\mathrm{QC}$ expression and $\mathrm{pE}-\mathrm{A} \beta$ formation in the $\mathrm{EWN}, \mathrm{LC}$ and $\mathrm{NbM}$ provides further evidence for $\mathrm{pE}-\mathrm{A} \beta$ formation by $Q C$ in vivo. Since $\mathrm{pE}-\mathrm{A} \beta$ confers exceptional neurotoxicity $[1,47]$ and since intraneuronal $\mathrm{pE}-\mathrm{A} \beta$ generation has been linked to neurodegeneration in animal models of AD [7, 72], QC-expressing EWN, LC and NbM neurons appear to be at high risk. Indeed, these neuronal populations are affected in $\mathrm{AD}$ and some clinical characteristics of $\mathrm{AD}$ patients such as dementia, anxiety, depression, compromised stress response and attention deficits $[4,9,21,35]$ could be-at least partially-attributed to compromised function of EWN, LC and $\mathrm{NbM}$ neurons. Moreover, in control subjects QC is expressed in all subcortical nuclei investigated without accompanying $\mathrm{pE}-\mathrm{A} \beta$ deposit formation. This indicates a yet unidentified physiological function for $\mathrm{QC}$ outside the hypothalamus, which does not normally lead to $\mathrm{pE}-\mathrm{A} \beta$ deposition or to neurodegeneration. In $\mathrm{AD}$, however, there is $\mathrm{pE}-\mathrm{A} \beta$ formation and neurodegeneration in LC, EWN and NbM. Thus, it appears that QC expression alone is not sufficient for $\mathrm{pE}-\mathrm{A} \beta$ formation and neurotoxicity, but a dysbalance in the expression of APP, its processing by $\beta$ - and $\gamma$-secretases and $\mathrm{N}$-terminal $\mathrm{A} \beta$ truncation have to occur to generate the pathogenic QC substrate. In conclusion, we postulate that among multiple mechanisms contributing to the pathogenesis of $\mathrm{AD}$, QC plays an important role in EWN, LC and NbM neurodegeneration and in pE-A $\beta$ plaque pathology, both locally and in the cortical and hippocampal target regions of these projection neurons. As a consequence, pharmacological QC inhibition should reduce $\mathrm{pE}-\mathrm{A} \beta$ production and exert beneficial effects on these neuronal populations.

Acknowledgments We thank R. Jendrek (Paul Flechsig Institute for Brain Research), H. Cynis, K. Schulz, M. Bornack, E. Scheel and M. Buchholz (Probiodrug) and S. Yu (Kinsmen Laboratory of Neurological Research) for technical assistance. This work was supported by the German Federal Department of Education, Science and Technology, BMBF grant \#3013185 to HUD. Aspects of this work were also supported by the Pacific Alzheimer Research Foundation to CS and PLM and by the 7th Framework Program Health of the European Commission (Neuropro, Grant Agreement \#223077) to SR. MM is member of the Graduiertenkolleg GRK 1097 funded by the German Research Foundation and of the $\mathrm{MD} / \mathrm{PhD}$ program at the University of Leipzig.

Open Access This article is distributed under the terms of the Creative Commons Attribution Noncommercial License which permits any noncommercial use, distribution, and reproduction in any medium, provided the original author(s) and source are credited.

\section{References}

1. Acero G, Manutcharian K, Vasilevko V et al (2009) Immunodominant epitope and properties of pyroglutamate-modified $\mathrm{A} \beta$ specific antibodies produced in rabbits. J Neuroimmunol 213:3946

2. Arendt T, Bigl V, Tennstedt A, Arendt A (1985) Neuronal loss in different parts of the nucleus basalis is related to neuritic plaque formation in cortical target areas in Alzheimer's disease. Neuroscience 14:1-14

3. Bachtell RK, Weitemier AZ, Galvan-Rosas A et al (2003) The Edinger-Westphal-lateral septum urocortin pathway and its relationship to alcohol consumption. J Neurosci 23:2477-2487

4. Berridge CW, Waterhouse BD (2003) The locus coeruleusnoradrenergic system: modulation of behavioral state and statedependent cognitive processes. Brain Res Rev 42:33-84

5. Bondareff W, Mountjoy CQ, Rossor RM, Iversen LL, Reynolds GP, Hauser DL (1987) Neuronal degeneration in the locus coeruleus and cortical correlates of Alzheimer's disease. Alzheimer Dis Assoc Disord 1:256-262

6. Busch C, Bohl J, Ohm TG (1997) Spatial, temporal and numeric analysis of Alzheimer changes in the nucleus coeruleus. Neurobiol Aging 18:401-406

7. Casas C, Sergeant N, Itier JM et al (2004) Massive CA1/2 neuronal loss with intraneuronal and $\mathrm{N}$-terminal truncated Abeta42 accumulation in a novel Alzheimer transgenic model. Am J Pathol 165:1289-1300

8. Christensen DZ, Kraus SL, Flohr A, Cotel MC, Wirths O, Bayer TA (2008) Transient intraneuronal $A \beta$ rather than extracellular plaque pathology correlates with neuron loss in the frontal cortex of APP/PS1 mice. Acta Neuropathol 116:647-655

9. Coyle JT, Price DL, DeLong MR (1983) Alzheimer's disease: a disorder of cortical cholinergic innervation. Science 219:11841190

10. Cullen MJ, Ling N, Foster AC, Pelleymounter MA (2001) Urocortin, corticotropin-releasing factor-2 receptors and energy balance. Endocrinology 142:992-999

11. Cynis H, Schilling S, Bodnar M et al (2006) Inhibition of glutaminyl cyclase alters pyroglutamate formation in mammalian cells. Biochim Biophys Acta 1764:1618-1625

12. D'Arrigo C, Tabaton M, Perico A (2009) N-terminal truncated pyroglutamyl beta amyloid peptide Abetapy3-42 shows a faster aggregation kinetics than the full-length Abeta1-42. Biopolymers 91:861-873

13. Damier P, Hirsch EC, Agid Y, Graybiel AM (1999) The substantia nigra of the human brain. I. Nigrosomes and the nigral matrix, a compartmental organization based on calbindin D28K immunohistochemistry. Brain 122:1421-1436

14. Forno LS (1978) The Locus coeruleus in Alzheimer's disease. J Neuropath Exp Neurol 37:614

15. Gaszner B, Jensen KO, Farkas J et al (2009) Effects of maternal separation on dynamics of urocortin 1 and brain-derived neurotrophic factor in the rat non-preganglionic Edinger-Westphal nucleus. Int J Dev Neurosci 27:439-451

16. German DC, Manaye KF, White CL III et al (1992) Diseasespecific patterns of locus coeruleus cell loss. Ann Neurol 32:667676

17. Hardy JA, Higgins GA (1992) Alzheimer's disease: the amyloid cascade hypothesis. Science 256:184-185

18. Hartlage-Rübsamen M, Staffa K, Waniek A et al (2009) Developmental expression and subcellular localization of glutaminyl cyclase in mouse brain. Int J Dev Neurosci 27:825-835

19. He W, Barrow CJ (1999) The A beta 3-pyroglutamyl and 11pyroglutamyl peptides found in senile plaque have greater beta- 
sheet forming and aggregation propensities in vitro than fulllength A beta. Biochemistry 38:10871-10877

20. Heneka MT, Ramanathan M, Jacobs AH et al (2006) Locus coeruleus degeneration promotes Alzheimer pathogenesis in amyloid precursor protein 23 transgenic mice. J Neurosci 26:1343-1354

21. Horn AK, Eberhorn A, Härtig W, Ardeleanu P, Messoudi A, Büttner-Ennever JA (2008) Perioculomotor cell groups in monkey and man defined by their histochemical and functional properties: reappraisal of the Edinger-Westphal nucleus. J Comp Neurol 507:1317-1335

22. Horn AK, Schulze C, Radtke-Schuller S (2009) The EdingerWestphal nucleus represents different functional cell groups in different species. Ann N Y Acad Sci 1164:45-50

23. Iwatsubo T, Odaka A, Suzuki N, Mizusawa H, Nukina N, Ihara $\mathrm{Y}$ (1994) Visualization of Abeta 42(43) and Abeta 40 in senile plaques with end-specific Abeta monoclonals: evidence that an initially deposited species is Abeta 42(43). Neuron 13:45-53

24. Iwatsubo T, Mann DM, Odaka A, Suzuki N, Ihara Y (1995) Amyloid beta protein (Abeta) deposition: Abeta 42(43) precedes Abeta 40 in Down syndrome. Ann Neurol 37:294-299

25. Jackisch R, Gansser S, Cassel JC (2008) Noradrenergic denervation facilitates the release of acetylcholine and serotonin in the hippocampus: towards a mechanism underlying upregulations described in MCI patients? Exp Neurol 213:345-353

26. Kalinin S, Gavrilyuk V, Polak $P$ et al (2007) Noradrenaline deficiency in brain increases $\beta$-amyloid plaque burden in an animal model of Alzheimer's disease. Neurobiol Aging 28:12061214

27. Konigsmark BW (1970) Methods for the counting of neurons. In: Nauta WHJ, Ebbesson SOE (eds) Contemporary research methods in neuroanatomy. Springer, Berlin, pp 315-380

28. Koob GF, Heinrichs SC (1999) A role of corticotropin-releasing factor and urocortin in behavioral responses to stressors. Brain Res 848:141-152

29. Liu K, Solano I, Mann D et al (2006) Characterization of Abeta11-40/42 peptide deposition in Alzheimer's disease and young Down's syndrome brains: implication of N-terminally truncated Abeta species in the pathogenesis of Alzheimer's disease. Acta Neuropathol 112:163-174

30. Loy R, Koziell DA, Lindsay JD, Moore RY (1980) Noradrenergic innervation of the adult rat hippocampal formation. J Comp Neurol 189:699-710

31. Mai JK, Assheuer J, Paxinos G (2004) Atlas of the human brain. Academic Press, San Diego

32. Mann DM, Yates PO, Marcyniuk B (1984) Monoaminergic neurotransmitter systems in presenile Alzheimer's disease and in senile dementia of Alzheimer type. Clin Neuropathol 3:199205

33. Marcyniuk NB, Mann DM, Yates PO (1986) The topography of cell loss from locus coeruleus in Alzheimer's disease. J Neurol Sci 76:335-345

34. Marcyniuk NB, Mann DM, Yates PO (1986) Loss of nerve cells from locus coeruleus in Alzheimer's disease is topographically arranged. Neurosci Lett 64:247-252

35. Marino MD, Bourdelat-Parks BN, Weinshenker D (2005) Genetic reduction of noradrenergic function alters social memory and reduces aggression in mice. Behav Brain Res 161:197-208

36. McColl G, Roberts BR, Gunn AP et al (2009) The Caenorhabditis elegans A $\beta 1-42$ model of Alzheimer's disease predominantly expresses A 33-42. J Biol Chem 284:22697-22702

37. McKhann G, Drachmann D, Folstein M, Katzman R, Price D, Stadlan EM (1984) Clinical diagnosis of Alzheimer's disease: report of the NINCDS-ADRDA work group under the auspices of Department of Health and Human Services Task Force on Alzheimer's disease. Neurology 34:939-944
38. Miravalle L, Calero M, Takao M, Roher AE, Ghetti B, Vidal R (2005) Amino-terminally truncated Abeta peptide species are the main component of cotton wool plaques. Biochemistry 44:10810-10821

39. Moreau JL, Kilpatrick G, Jenck F (1997) Urocortin, a novel neuropeptide with anxiogenic-like properties. Neuroreport 8:16971701

40. Muresan Z, Muresan V (2008) Seeding neuritic plaques from the distance: a possible role for brainstem neurons in the development of Alzheimer's disease. Neurodegener Dis 5:250-253

41. Paxinos G, Huang XF, Toga AW (2000) The rhesus monkey brain in stereotaxic coordinates. Academic Press, San Diego

42. Paxinos G, Huang XF (1995) Atlas of the human brainstem. Academic Press, San Diego

43. Piccini A, Russo C, Gliozzi A et al (2005) Beta-amyloid is different in normal aging and in Alzheimer's disease. J Biol Chem 280:34186-34192

44. Roßner S, Ueberham U, Schliebs R, Perez-Polo JR, Bigl V (1998) The regulation of amyloid precursor protein metabolism by cholinergic mechanisms and neurotrophin receptor signaling. Prog Neurobiol 56:541-569

45. Rüb U, Del Tredici K, Schultz C, Büttner-Ennever JA, Braak H (2001) The premotor region essential for rapid vertical eye movements shows early involvement in Alzheimer's diseaserelated cytoskeletal pathology. Vision Res 41:2149-2156

46. Russo C, Schettini G, Saido TC et al (2000) Presenilin-1 mutations in Alzheimer's disease. Nature 405:531-532

47. Russo C, Violani E, Salis S et al (2002) Pyroglutamate-modified amyloid beta-peptides-AbetaN3(pE)-strongly affect cultured neuron and astrocyte survival. J Neurochem 82:1480-1489

48. Ryabinin AE, Tsivkovskaia NO, Ryabinin SA (2005) Urocortin 1-containing neurons in the human Edinger-Westphal nucleus. Neuroscience 134:1317-1323

49. Saido TC (1998) Alzheimer's disease as proteolytic disorders: anabolism and catabolism of beta-amyloid. Neurobiol Aging 19:S69-S75

50. Saido TC, Iwatsubo T, Mann DM, Shimada H, Ihara Y, Kawashima S (1995) Dominant and differential deposition of distinct beta-amyloid peptide species, Abeta $\mathrm{N} 3(\mathrm{pE})$, in senile plaques. Neuron 14:457-466

51. Saido TC, Yamao H, Iwatsubo T, Kawashima S (1996) Aminoand carboxyl-terminal heterogeneity of beta-amyloid peptides deposited in human brain. Neurosci Lett 215:173-176

52. Schilling S, Hoffmann T, Manhart S, Hoffmann M, Demuth HU (2004) Glutaminyl cyclases unfold glutamyl cyclase activity under mild acid conditions. FEBS Lett 563:191-196

53. Schilling S, Lauber T, Schaupp M et al (2006) On the seeding and oligomerization of pGlu-amyloid peptides (in vitro). Biochemistry 45:12393-12399

54. Schilling S, Zeitschel U, Hoffmann T et al (2008) Glutaminyl cyclase inhibition attenuates pyroglutamate Abeta and Alzheimer's disease-like pathology. Nat Med 14:1106-1111

55. Schilling S, Appl T, Hoffmann T et al (2008) Inhibition of glutaminyl cyclase prevents pGlu-A $\beta$ formation after intracortical/ hippocampal microinjection in vivo/in situ. J Neurochem 106:1225-1236

56. Schlenzig D, Manhart S, Cinar Y et al (2009) Pyroglutamate formation influences solubility and amyloidogenicity of amyloid peptides. Biochemistry 48:7072-7078

57. Scinto LF, Daffner KR, Dressler D et al (1994) A potential noninvasive neurobiological test for Alzheimer's disease. Science 266:1051-1054

58. Scinto LF, Wu CK, Firla KM, Daffner KR, Saroff D, Geula C (1999) Focal pathology in Edinger-Westphal nucleus explains pupillary hypersensitivity in Alzheimer's disease. Acta Neuropathol 97:557-564 
59. Scinto LF, Frosch M, Wu CK, Daffner KR, Gedi N, Geula C (2001) Selective cell loss in Edinger-Westphal in asymptotic elders and Alzheimer's patients. Neurobiol Aging 22:729-736

60. Selkoe DJ, Schenk D (2003) Alzheimer's disease: molecular understanding predicts amyloid based therapeutics. Annu Rev Pharmacol Toxicol 43:545-584

61. Sergeant N, Bombois S, Ghestem A et al (2003) Truncated betaamyloid peptide species in pre-clinical Alzheimer's disease as new targets for the vaccination approach. J Neurochem 85:15811591

62. Shin RW, Ogino K, Kondo A et al (1997) Amyloid beta-protein (Abeta) 1-40 but not Abeta1-42 contributes to the experimental formation of Alzheimer disease amyloid fibrils in rat brain. J Neurosci 17:8187-8193

63. Spina M, Merlo-Pich E, Chan RK et al (1996) Appetitesuppressing effects of urocortin, a CRF-related neuropeptide. Science 273:1561-1564

64. Vanderstichele H, De Meyer G, Andreasen N et al (2005) Aminotruncated beta\}-amyloid42 peptides in cerebrospinal fluid and prediction of progression of mild cognitive impairment. Clin Chem 51:1650-1660

65. Vaughan J, Donaldson C, Bittencourt J et al (1995) Urocortin, a mammalian neuropeptide related to fish urotensin $\mathrm{I}$ and to corticotropin-releasing factor. Nature 378:287-292

66. Vida I, Halasy K, Szinyei C, Somogyi P, Buhl EH (1998) Unitary IPSPs evoked by interneurons at the stratum radiatum-stratum lacunosum-moleculare border in the CA1 area of the rat hippocampus in vitro. J Physiol 506:755-773

67. Weinshenker D (2008) Functional consequences of locus coeruleus degeneration in Alzheimer's disease. Curr Alzheimer Res 5:342-345

68. Weitemier AZ, Tsivkovskaia NO, Ryabinin AE (2005) Urocortin 1 distribution in mouse brain is strain-dependent. Neuroscience 132:729-740

69. Weninger SC, Peters LL, Majzoub JA (2000) Urocortin expression in the Edinger-Westphal nucleus is up-regulated by stress and corticotropin-releasing hormone deficiency. Endocrinology 141:256-263

70. Whitehouse PJ, Price DL, Clark AW, Coyle JT, DeLong MR (1981) Alzheimer's disease: evidence for selective loss of cholinergic neurons in the nucleus basalis. Ann Neurol 10:122-126

71. Wilcock GK, Esiri MM, Bowen DM, Hughes AO (1988) The different involvement of subcortical nuclei in senile dementia of Alzheimer's type. J Neurol Neurosurg Psychiatry 51:842-849

72. Wirths O, Breyhan H, Cynis H, Schilling S, Demuth HU, Bayer TA (2009) Intraneuronal pyroglutamate-Abeta 3-42 triggers neurodegeneration and lethal neurological deficits in a transgenic mouse model. Acta Neuropathol 118:487-496

73. Wirths O, Bethge T, Marcello A et al (2010) Pyroglutamate Abeta pathology in APP/PS1KI mice, sporadic and familial Alzheimer's disease. J Neural Transm 117:85-96 